\title{
NEW PATHWAYS TO INDUSTRIALISATION IN TANZANIA: THEORETICAL AND STRATEGIC CONSIDERATIONS
}

\section{Anders Aeroe}

\section{INTRODUCTION}

This article discusses the relevance of flexible specialisation in a Tanzanian context. The first Section of the article draws together key aspects of the new approach. The second Section suggests that a distinction between flexible specialisation as a positive and normative approach is necessary, and that industrialisation should be understood as a locally embedded process. The third Section adopts the positive approach and explores the relevance of flexible specialisation to the industrial development of small town Tanzania. The fourth Section, which employs flexible specialisation from a normative perspective, discusses how to promote Tanzanian industrial development. The article concludes that the ongoing Structural Adjustment Programme should be supplemented with regional and district supportive industrial policies, as these are essential for small town industrial development.

\section{NEW APPROACHES}

In recent years, Fordism with its emphasis on large scale, Taylorist organised production has been challenged all over the world. In Europe, in the USA and in South-East Asia the regimes of Fordism are challenged by greater emphasis on sub-contracting and other quasi-integrated systems involving a relatively deep social division of labour. ${ }^{1}$ In the Soviet Union and Eastern Europe large parastatal enterprises are being privatised, and privately owned small and mediumsized enterprises are emerging. The same trend can be observed in a number of developing countries, including African countries, as a consequence of the recent World Bank initiated Economic Recovery and Structural Adjustment Programmes. If one should identify one major trend in these developments it is the retreat of large scale mass production (which never operated very efficiently in the African setting anyway) and of direct government involvement in production.

New theoretical approaches have been developed recently as a response to these developments: the flexible specialisation approach (e.g. Piore and Sabel 1984; Scott 1988; Storper 1989), the Scandinavian network approach (e.g. NordReFo 1990; Pedersen 1989), and the Italian discussion about industrial districts (e.g. Goodman and Bamford 1989). All these approaches emphasise the advantages of clustered, cooperating small and medium sized enterprises, the role of the state in planning for local and regional development, and the interplay between entrepreneurial action and the societal structures. Hence, they all stress that industrial production can happen via the use of other techniques and other ways of organisation than those employed by Fordist mass production. Furthermore, they highlight the importance of inter-personal relations and thereby indirectly the local embeddedness of industrial production and the role of the local technological capability. Finally, they indicate that emphasis has to be directed towards groups of networking enterprises and their socio-economic environment and not only towards the single enterprise to capture these dynamics.

\section{FLEXIBLE SPECIALISATION IN A TANZANIAN CONTEXT}

The flexible specialisation approach has also been applied to development in the industrialising countries (e.g. Riedel and Schmitz 1989; Sabel 1986; Storper 1991). Piore and Sabel (1984) did not provide a clear cut definition of flexible specialisation, and hence there has been some room for interpretation when applying this concept in a specific situation. However, before applying the flexible specialisation approach to the analysis of the industrialisation process in Tanzania, the implications of the socio-economic setting in which the flexible specialisation approach was originally developed have to be made clear.

The flexible specialisation approach was originally developed in a context of advanced market and contract relations where enterprise cooperation was legally regulated and where the uncertainty is less than in Tanzania. Therefore, the influence from and consequences of power structures were never well developed in the original approach. Instead the advantages of a social division of labour and a close cooperation between enterprises have been highlighted.

In Tanzania, an overlap between the different networks (business, political and family) in which a small enterprise is involved means that the power structures play an increasing role within the networks. Power 
structures prevailing within one sphere (e.g. the political) also influence the other spheres, not least the business sphere. Furthermore, the power structures, and the uncertainties on which these power structures are based, and the mutual obligations between patron and client, may hamper the cooperation between the client (e.g. a small entrepreneur) and other actors. Finally, the different power positions of the entrepreneurs involved in an industrial network and the lack of legal regulation in Tanzania may further hinder the development of enterprise cooperation.

However, the sort of cooperation implied by flexible specialisation requires a higher degree of commoditisation of social relations and a stronger inter-firm division of labour than those found in Tanzania. This is not to say that flexible specialisation is of no relevance in a Tanzanian context, but rather that one has to distinguish between flexible specialisation as a positive and a normative approach. A positive approach is used in analysis to find out whether flexible specialisation exists in a given situation. A normative approach is used to make recommendations on the future development of an industrial sector.

The positive approach reveals that flexible specialisation can be observed e.g. in Ghana (Riedel and Schmitz 1989; Dawson in this Bulletin), but not in Tanzania. Ghana has, in contrast to Tanzania, a long entrepreneurial tradition and hence substantial private enterprise development and inter-firm division of labour. In Tanzania, these enterprises are about to be established, apart from enterprises in service and trade owned by Asians and Arabs.

Although flexible specialisation does not exist in Tanzania, significant methodological gains from using the approach in an analysis can be achieved. The most important gains are the conceptualisation of industrialisation as a locally embedded process, and the focus on networking and on technological capability as essential elements in this process. Furthermore, the flexible specialisation approach highlights that small enterprises not only represent a residual in the industrial development, as indicated by both the modernisation (e.g. Rostow 1960) and neo-Marxist (e.g. Santos 1979) development approaches. These observations are no less relevant in Tanzania, where the ongoing reorientation away from highly inefficient, large parastatal enterprises ${ }^{2}$ is a necessity for a sustainable industrialisation process to develop.

\section{Previously, Tanzania employed an import substitution}

industrialisation strategy. During the implementation of this strategy the impact of the local business environment was neglected, and consequently the troubles and costs related to the implementation of a viable industrialisation process were underestimated. This is not to say that the focus should be on the local factors only, but rather that an industrialisation process must be understood as an interplay between the international, national and local structures, and the enterprise behaviour within these structures.

The dynamics of a particular mode of production are expressed at the macro level in a certain industrial organisation, a certain division of labour, and certain technology and labour market processes (Scott and Storper 1986). These dynamics are affected at the local level by the socio-cultural specificities of the single community. Outside the metropolis Dar es Salaam, ind ustrialisation in Tanzania primarily happens in the small and medium-sized towns. Within these towns, the socio-cultural specificities can be sub-divided into agglomeration dynamics and the local socio-cultural environment, as illustrated in Figure 1.

The agglomeration dynamics and the local sociocultural environment are mutually interacting, and produce a flow of goods, services and information, influencing the action of the single enterprise and entrepreneur involved in the small town business environment.

In the development debate, small enterprises have typically either been conceived as subcontractors (in the more industrialised countries) or as petty producers serving as a platform for reproduction of the poorer segments of the population (in the less industrialised countries). However, both views can be criticised because they perceive small enterprises as a residual to capitalist development. The global history of industrial development indicates that niches for small enterprises constantly emerge as the production structure develops, while other niches disappear during this process. Furthermore, both approaches neglect the potential of small agglomerated networking enterprises. Instead, small enterprises must be perceived as an integral part of the industrial development, and hence a uniform pattern for their development must be rejected.

The development potential and possibility of the single enterprise depends on the one hand on the capacity and resources of the enterprise and on the other hand on the actual room for the given activity on a competitive

parastatal ownership allows political factors to influence the management of the enterprises, and consequently the enterprises have run on political rather than on commercial premises. Together, these two factors have caused many large parastatal enterprises to be kept alive via heavy subsidising. 
Figure 1: The business environment of small town enterprise

\section{Overall societal structures}

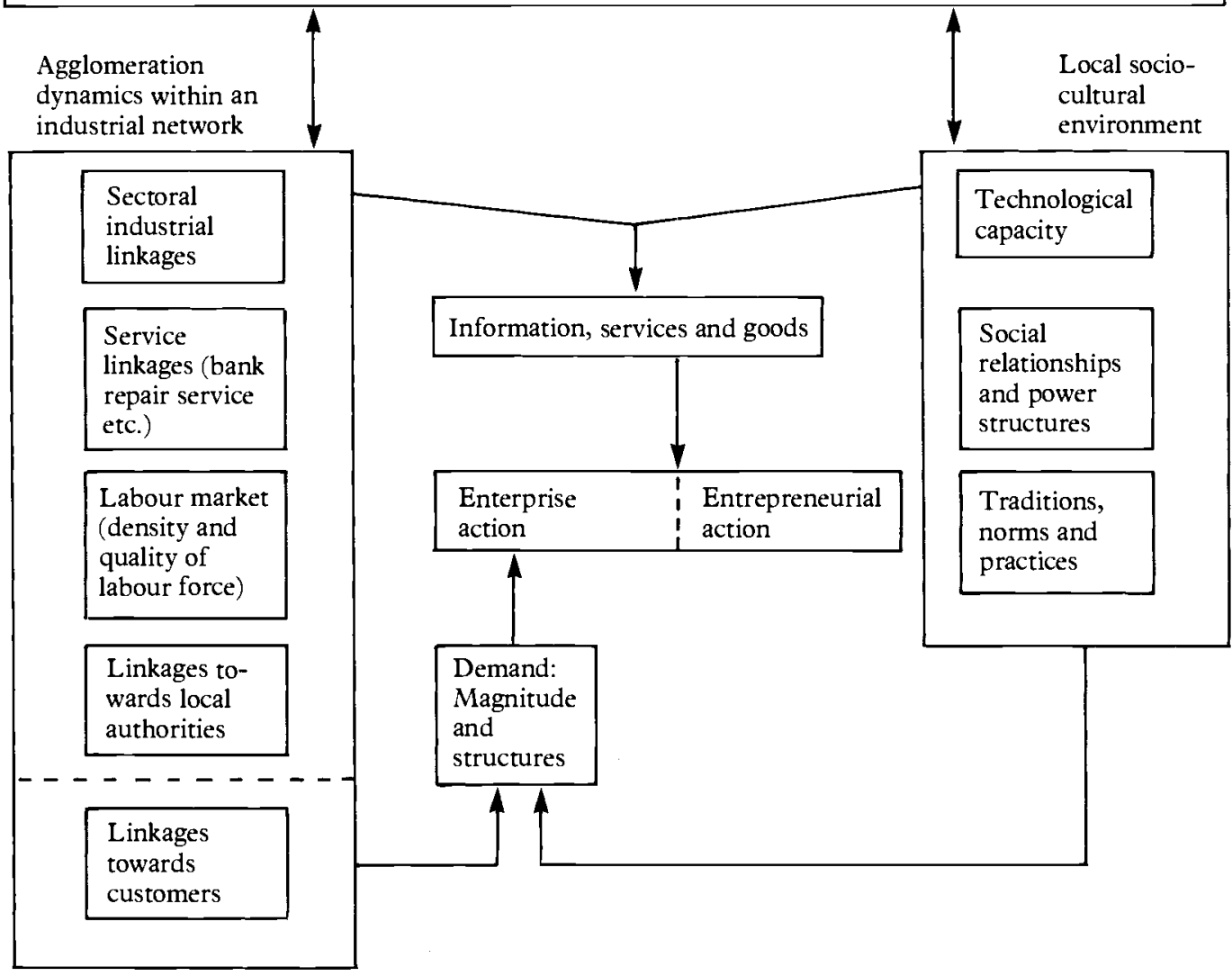

market. Consequently, the analysis of local enterprise development and of the potentials of local enterprises has to be sector specific, as well as involving the specific historical and spatial conditions, which again are affected by the overall structural conditions of the given society.

Agglomeration plays a very important role for local enterprise development in South-East Africa, however, without implying that all business networks are agglomerated, and that collective efficiency occurs only because small firms cluster. Frequent transactions within a business network demand a certain proximity. It takes density to cultivate the required contacts not only with other enterprises but also with influential people within the local administration, bank and party, with employees, suppliers and customers. Furthermore, the mutual processes of learning and innovation and an easy accessibility to the required pool of skills also demands proximity. The ever changing structural conditions make this proximity even more important for the ability to coordinate and undertake the required adjustments within the network. The importance of agglomeration economies establishes the small and medium-sized towns as nuclei for ongoing regional enterprise development in Tanzania, and highlights at the same time the importance of district and regional development policies.

However, even within a specific group of enterprises with in the same town and with approximately the same size, vast variations might be indentified, highlighting the influence of the technological capability. This capability $\mathbf{n}^{\text {nt }}$ only refers to the technical ability but 
also to the innovative, commercial and organisational ability. On the basis of these theoretical considerations, an empirical study of the small town construction industry was carried out in Tanzania in 1989. Enterprise strategies, networks and technological capabilities were studied with the purpose of identifying the role and potentials of the small town construction enterprises. The study covered 73 enterprises within the construction industry in three small and medium-sized towns (Makambako, Niombe and Iringa) in the Iringa Region in the Southern Highlands. ${ }^{3}$ In the following, findings from one of the three towns, Makambako, will be presented.

\section{SMALL TOWN INDUSTRIAL DEVELOPMENT IN TANZANIA}

During the last two decades Makambako has experienced a rapid growth, from less than 1,000 people in the late 1960 s to more than 15,000 people in 1989. The rapid growth of the town is a combination of increased local demand caused by the introduction of high yielding hybrid maize in the mid-1970s and of infrastructural development of rail and roads from the mid-1970s onwards, making Makambako an important junction for trade and services. Finally, the trade liberalisation, introduced in 1986 as a part of the Economic Recovery Programme agreed upon with the International Monetary Fund, further turned investments into private business.

In Makambako, the commercial activities include more than 250 shops, 56 restaurants and guest houses, four petrol stations and 37 bars (Ardhi Institute 1989). To these activities have to be added a large number of market activities, an upcoming furniture industry and a booming local construction industry.

The industrialisation process in Makambako has happened without assistance from government or donor agencies, but has been heavily influenced by favourable overall structural conditions: the infrastructure development, increasing purchasing power in the hinterland and the liberalisation policy, making private savings available for investments. No large parastatal production units have been implanted in the town and local privately owned enterprises dominate within production, services and trade.

The fast economic development in Makambako has attracted many experienced business people. Most of the businessmen have grown up in the rural surroundings but they have typically got their experience from years of public or private employment in Dar es Salaam or in a regional town.

The rapid growth of the town has allowed many enterprises to operate within the construction industry. All in all, 96 enterprises were at the same time competing and cooperating with each other. The three major groups of enterprises were non-registered contractors (builders), masonry units (masons and helpers) and carpenters.

An emerging division of labour could be observed, particularly among carpenters. However, in most cases this division of labour was not based upon a process specialisation, as indicated by the flexible specialisation approach, but rather upon a product specialisation. Some enterprises were primarily producing furniture while others were primarily producing doors and window frames. However, an emerging process specialisation could be observed in the sense that one carpenter was 'importing' wood which he planed on his machine and resold to the other carpenters, who only possessed hand tools. But in general, enterprise cooperation primarily involved exchange of ideas and designs and a mutual adjustment of prices, so as not to undercut each other. Some of the young newcomers employed a strategy to undercut the agreed price level to attract customers. This strategy created tensions between them and the established enterprises. However, due to the rapidly expanding market, this tension was not as pronounced in Makambako as in the neighbour town Njombe, which was not experiencing the same rapid economic growth and therefore experienced more intense competition.

Hardwood was not available in the rural surroundings and therefore well-functioning business linkages to the suppliers in other regions were very important for the carpenters. Also the linkages towards the bank, the public authorities, the missions and the customers played an essential role for the enterprises. The bank represents the only source of finance apart from own financing, as a private loan market is non-existent and the public Small Industry Development Organisation played virtually no role in the enterprises' development in Makambako. In a very few cases, enterprise owners had obtained loans or gifts from relatives or friends.

Enterprise licences are bought from the local public authorities in Njombe, and taxes are paid to these authorities. The level of taxation is assessed by the tax collector and is therefore negotiable and influenced by personal relations. The missions play an important role in vocational training, and many missions also provide services to artisans trained by them, e.g. they import tools which they resell for local currency and thereby overcome the foreign currency constraint.

Nearly all private jobs were obtained because the customers had seen previous work, via personal acquaintance or via recommendations. Therefore,

${ }^{3}$ For a full description of this survey, see Aeroe (1991). 
technological capability in combination with personal linkages played a very important role for attracting customers. The local enterprises seldom worked as sub-contractors for large non-local enterprises. The large enterprises were typically working on donor financed public jobs offered via tendering in Dar es Salaam. These enterprises preferred to bring their own experienced staff and, only hired the locals on an employee basis. Consequently, the local enterprises gained limited experience from these arrangements, and their technological capability was, in general, not very high. This low technological capability was, among other things, closely related to the low social status of vocational training in Tanzania compared to literacy studies. In Tanzania, the enrolment at vocational training centres versus secondary schools is 1:11 (Aeroe 1991).

However, vast variations were observed within the surveyed enterprises in Makambako, both according to the intensity of their network and their technological capability. The most prosperous entrepreneurs were typically running quality, machine based productions, and the prosperous builders and masons had several jobs waiting for them. These entrepreneurs were also of ten involved in other business activities, e.g. running a large farm or a shop.

Diversification, and thereby the spread of risk, was a key strategy for the successful business peoples' investment patterns in Makambako. In the insecure Tanzanian economic environment combined with the rapid economic growth in the region, diversification allows, at the same time, the investor to get fast returns from services (bars, guest houses, minibuses, etc.), medium term returns from production (furniture, metalwork, etc.) and trade (on the market or via a shop), and long term returns from investments in rental buildings (the demand for rented rooms in Makambako is very high) and in children's education. Education puts a young family member on a track which might lead to a future position as a patron with control over resources.

The development of business activities in Makambako has happened virtually without government support. Until the introduction of the Economic Recovery Programme in 1986 private enterprise development was looked upon with suspicion. Furthermore, the urban development policies of the central government have in practice not been concerned with the development of small towns below the regional centres. The role of the local authorities is, from the perspective of the local businessmen, mainly to control and extract revenues (tax collection, issuing business licences, implementation of rules and regulations, etc.).

The rapid expansion of the town has allowed substantial room for nearly all kinds of business activities to prosper. However, this rapid pace will not continue forever, and the future development of small scale activities will be retarded if district, regional or central policy measures are not taken into consideration to support development of an increased technological capacity, local cooperation and networking, and appropriate markets, and also to adjust macro economic policies biased against small scale production.

\section{FURTHER PERSPECTIVES AND STRATEGIC CONSIDERATION}

Flexible specialisation, employed both as a positive and a normative approach, has been shown to be very useful in the analyses of the Tanzanian small town industrialisation process.

In Tanzania, a dual industrial structure has been identified. On the one hand a large scale, city based, inefficient industrial structure surviving on subsidies and protection. On the other hand a small scale production structure based on local demand and with substantial linkages to the local business environment, but in general with a limited technological capability and accumulation, and hence ability to develop production.

An overall target for future development should be to develop the complementarity between the large and small enterprises in a more systematic way. An essential future role of the small enterprises is to create supportive functions for the large enterprises, e.g. within transportation and sales, to increase efficiency of the large enterprises, and to produce goods not produced by the large enterprises, typically based upon local materials and directed towards the local market.

Trade and import liberalisation, which are essential elements of the Economic Recovery Programme, have caused a substantially increased import of quality products sold at high prices. The ERP has also caused an increase of general purchasing power, allowing more room for both locally produced and imported goods. However, many obstacles against improving the performance of small town enterprises were identified: low technological capability and accumulation, limited division of labour, unstable business environment, prevalence of power structures partly based upon this uncertainty and an Economy of Affection (Hyden 1983), and policies and socio-cultural norms and traditions biased against small enterprise development. Thus improving local industrial production is a multifaceted problem, involving both the enterprises and their local business environment.

To narrow the gap between the large and small enterprises one should particularly aim at improving the technological capability of the small enterprises. 
However, the development of this capability is not only dependent upon the single enterprise but also upon the local business environment. Hence, support should also be provided to this environment, including business organisations, local government, banks, etc. and not only towards the single enterprise.

Finally, one must accept that it will take decades to create the necessary economic and technological foundation for industrial development. Hence, arrangements reducing the importance of the single individual should be taken into consideration, not least because of the limited enterprise take over from generation to generation. ${ }^{4}$

All in all, the factors influencing industrial development in Tanzania make future development very bleak, as these factors in general work against the creation of the necessary 'enabling environment' for local enterprise development. The district and regional policy aspect is essential as these policies can be directed specifically towards the needs of the small town enterprises. However, in the industrialisation debate in Tanzania these policies are in general neglected, and only the macro-economic policies are discussed. Therefore, the present Economic Recovery Programme and its macroeconomic policies should be supplemented with supporting programmes - particularly at the district and regional level - so as to improve innovative capability and enterprise services, and promote vocational training and enterprise cooperation. Furthermore, establishment of business associations should be encouraged, as these can serve as a platform for articulation of the industries' needs.

4 Businessmen often encourage their children (at least their sons) to take higher education, thereby hampering their own business development in the long run, as these young educated people are very

reluctant to take over their fathers' business. Therefore, the business is often closed down when the founder retires. Rasmussen (this Bulletin) found the same in Zimbabwe.

\section{REFERENCES}

Aeroe, A., 1991, 'Rethinking industrialization - from a national to a local perspective. A case study of the industrialization process in Tanzania with particular emphasis at the construction industry', PhD Dissertation, Centre for Development Research and Copenhagen Business School, Copenhagen

Ardhi Institute, 1989, Makambako Development Plan, Department of Urban and Rural Planning, Ardhi Institute, Dar es Salaam

Hyden, G., 1983, No Shortcuts to Progress. African Development Management in Perspective, Heinemann, London

NordReFo, 1990, 'Networks and regional development', NordReFo, No 1

Pedersen, P. O., 1989, 'The role of small enterprises and small towns in the developing countries - and in the developed', CDR Project Paper 89.1, Centre for Development Research, Copenhagen

Piore, M. J. and Sabel, C. F., 1984, The Second Industrial Divide, Basic Books, New York

Riedel, J. and Schmitz, H., 1989, Grass-root Industrialization in a Ghanaian Tozw, Weltforum Verlag, München

Rostow, W., 1960, The Stages of Economic Growth: A Noncommunist Manifesto, Cambridge University Press, Cambridge

Sabel, C., 1986, 'Changing models of economic efficiency and their implications for industrialization in the Third World' in A. Foxley et al (eds.) Development, Democracy and the Art of Trespassing, University of Notre Dame Press, Indiana

Santos, M., 1979, The Shared Space, Methuen, London

Scott, A. J., 1988, New Industrial Spaces: Flexible Production Organization and Regional Development in North America and Western Europe, Pion, London

-and Storper, M. (eds.), 1986, Production, Work, Territory: The Geographical Anatomy of Industrial Capitalism, Allen and Unwin, Boston

Storper, M., 1989, 'The transition to flexible specialization in the US film industry: External economies, the division of labour, and the crossing of industrial divides', in Cambridge fournal of Economics, 13:273-305

-1991, Industrialization, Economic Development and the Regional Question in the Third World: From Import Substitution to Flexible Production, Pion, London 